\title{
C3 glomerulopathy and current dilemmas
}

\author{
Naoko Ito $^{1} \cdot$ Ryuji Ohashi $^{2} \cdot$ Michio Nagata $^{1}$ (i)
}

Received: 23 August 2016/ Accepted: 31 October 2016/Published online: 23 November 2016

(c) The Author(s) 2017. This article is an open access publication

\begin{abstract}
C3 glomerulopathy (C3G) is a recently identified disease entity caused by dysregulation of the alternative complement pathway, and dense deposit disease (DDD) and $\mathrm{C} 3$ glomerulonephritis $(\mathrm{C} 3 \mathrm{GN})$ are its components. Because laboratory detection of complement dysregulation is still uncommon in practice, "dominant $\mathrm{C} 3$ deposition by two orders greater than that of immunoglobulins in the glomeruli by immunofluorescence", as stated in the consensus report, defines C3G. However, this morphological definition possibly includes the cases with glomerular diseases of different mechanisms such as post-infectious glomerulonephritis. In addition, the differential diagnosis between DDD and C3GN is often difficult because the distinction between these two diseases is based solely on electron microscopic features. Recent molecular and genetic advances provide information to characterize $\mathrm{C} 3 \mathrm{G}$. Some $\mathrm{C} 3 \mathrm{G}$ cases are found with genetic abnormalities in complement regulatory factors, but majority of cases seem to be associated with acquired factors that dysregulate the alternative complement pathway. Because clinical courses and prognoses among glomerular diseases with dominant $\mathrm{C} 3$ deposition differ, further understanding the background mechanism, particularly complement dysregulation in $\mathrm{C} 3 \mathrm{G}$, is needed. This may resolve current dilemmas in practice and shed light on novel targeted
\end{abstract}

The original version of this article was revised due to a retrospective Open Access order.

Michio Nagata

nagatam@md.tsukuba.ac.jp

1 Kidney and Vascular Pathology, Faculty of Medicine, University of Tsukuba, 1-1-1, Tennodai, Tsukuba, Ibaraki 305-8577, Japan

2 Department of Diagnostic Pathology, Nippon Medical School Hospital, 1-1-5, Sendagi, Bunkyo-ku, Tokyo 113-8603, Japan therapies to remedy the dysregulated alternative complement pathway in $\mathrm{C} 3 \mathrm{G}$.

Keywords C3 glomerulopathy - Dense deposit disease C3 glomerulonephritis - Membranoproliferative glomerulonephritis - Alternative complement pathway . Dominant C3 deposition

\section{Introduction}

C3 glomerulopathy $(\mathrm{C} 3 \mathrm{G})$ is an emerging kidney disease caused by dysregulation of the alternative complement pathway [1-5]. The characteristic pathology of this disease is glomerular depositions of dominant $\mathrm{C} 3$ with absent or weak immunoglobulins $[6,7]$. Therefore, $\mathrm{C} 3 \mathrm{G}$ is basically diagnosed by immunofluorescence (IF) and it can reveal various patterns of glomerular injuries by light microscopy (LM) $[6,7]$.

Following the recent trend of pathogenesis-based reclassification of glomerular diseases, glomerulonephritis associated with alternative complement dysregulation is collectively referred to as $\mathrm{C} 3 \mathrm{G}[1,8]$. Because laboratory detection of alternative complement dysregulation is still uncommon in current practice, predominant $\mathrm{C} 3$ deposition by IF is an initial finding that suggests C3G. However, glomerular diseases caused by mechanisms other than alternative complement dysregulation may occasionally satisfy "C3-dominant deposition with scanty immunoglobulins" as stated in the current consensus report [6]. Postinfectious glomerulonephritis (PIGN) is an immune complex-mediated glomerulonephritis that sometimes displays dominant C3 deposition by IF [9]. In addition, differential diagnosis between two variants of $\mathrm{C} 3 \mathrm{G}$, dense deposit disease (DDD) and $\mathrm{C} 3$ glomerulonephritis (C3GN), is 
necessary if they show different clinical courses and treatment responses. DDD is highlighted by dense osmiophilic intramembranous deposition by electron microscopy (EM), and $\mathrm{C} 3 \mathrm{GN}$ is diagnosed when it lacks such characteristics seen in DDD [6]; nevertheless, the distinction between these two diseases is often difficult $[6,10]$. Clearly, pathogenesisbased classification in glomerular diseases is an important prospect for appropriate therapies, but the entity of $\mathrm{C} 3 \mathrm{G}$ still presents dilemmas in diagnostic practice by lack of clear definition and pathogenic basis. We review the current status of $\mathrm{C} 3 \mathrm{G}$ and dilemmas that may bring a more distinct definition and accurate therapies for patients with alternative complement dysregulation.

\section{MPGN and C3 glomerulopathy}

The idea of $\mathrm{C} 3 \mathrm{G}$ seems to be derived from inconsistent clinicopathological features of membranoproliferative glomerulonephritis (MPGN). MPGN was described initially by hypocomplementemia-associated glomerulonephritis characterized by glomerular capillary wall thickening with hypercellularity in the glomerular tuft [11]. MPGN is basically a LM-based disease entity and became subclassified into three types by the location of electron-dense deposits. Dense deposits in MPGN type I present mainly in the subendothelial spaces [12]. In contrast, those in MPGN type II/DDD are found in the lamina densa with characteristic highly dense, continuous features and often seen in other glomerular compartments [12, 13]. MPGN with a combination of subepithelial, subendothelial, and intramembranous deposits was classified as MPGN type III, which was further subclassified into two forms: the Burkholder variant and the Strife and Anders variant [14-16]. Inconsistent IF patterns among three types of MPGN may be one of the background ideas of C3G. Immunofluorescent findings revealed variety of patterns and were inconsistent even in one subtype. MPGN type I generally reveals granular or fringe patterns of $\operatorname{IgG}$ and C3 deposits along the capillary loop [17]. In DDD, however, most cases exhibit isolated or dominant C3 deposition with linear or granular patterns in the mesangium and in the capillary loops [17-19]. On the other hand, some studies have reported segmental immunoglobulin deposition in about half of the cases with DDD [20, 21]. In MPGN type III, IF typically shows granular $\mathrm{IgG}$ and $\mathrm{C} 3$ depositions in the Burkholder variant [14], whereas it shows dominant C3 deposition with or without $\operatorname{IgG}$ in the Strife and Anders variant [15]. In fact, $8 \%$ of MPGN type I cases and $10.4 \%$ of MPGN type III cases, mostly the Strife and Anders variant, showed isolated C3 deposition [21]. This deposit-based subclassification by EM together with IF has suggested distinct pathogenic mechanisms underlying some cases with MPGN, the dysregulated alternative complement pathway.

\section{Alternative complement pathway}

The complement system plays a crucial role in innate immunity and augments immune effectors in acquired immunity by antibody removal, recruitment and activation of leukocytes, phagocytosis, and cell membrane lysis via membrane attack complex. Complement activation occurs through the classical, lectin, and alternative complement pathways, and the cleavage of $\mathrm{C} 3$ plays a common and key role in the effector functions for all the pathways [22].

Activation of the alternative complement pathway is uniquely initiated by the spontaneous hydrolysis of $\mathrm{C} 3$ called "tick-over", and it occurs continuously at low levels in ordinary states [22]. There are several complement regulatory mechanisms in plasma and on cell surfaces to keep its activation at low levels because overactivation of the complement system can lead to injury of our own cells and tissues as attacking principle pathogens [22, 23]. Several factors that regulate the complement function are called complement regulatory factors (CRFs), including complement factor $\mathrm{H}(\mathrm{CFH})$, complement factor H-related proteins (CFHR), complement factor I (CFI), membrane cofactor protein (MCP), and complement factor B (CFB) $[22,23]$. They regulate the complement activation in plasma "fluid phase activation" and on cell surface "solid phase activation" [23]. CFH is the key regulator of the alternative complement pathway mainly in fluid phase by accelerating $\mathrm{C} 3$ convertase decay. $\mathrm{CFH}$ and CFHR genes share high homology in their DNA sequences, and their proteins interact to stabilize the complement pathway. CFI is a serine protease in the serum that cleaves $\mathrm{C} 3 \mathrm{~b}$ and $\mathrm{C} 4 \mathrm{~b}$ in the presence of cofactors, such as MCP which is a cellsurface complement regulator. CFB binds $\mathrm{C} 3 \mathrm{~b}$ and stabilizes C3 convertase [22, 23]. Dysfunction of CRFs promotes amplification of $\mathrm{C} 3 \mathrm{~b}$, leading to alternative complement overactivation as discussed in the following.

\section{Alternative complement dysregulation in $\mathrm{C3}$ glomerulopathy}

\section{History of the detection of alternative complement dysregulation in $D D D$}

In 1963, Berger et al. first described DDD as a glomerulonephritis with unique and extremely osmiophilic electron-dense deposits in glomerular basement membrane (GBM) [24]. In the early 1970s, DDD was reported as an anomaly of GBM among MPGN cases [13]. The composition of this peculiar intramembranous deposition in DDD 
has long been a mystery. The intramembranous electrondense substance in DDD was first considered to be an accumulation of glycoprotein membrane material. This was merely speculation based on the increase of sialic acid and the lack of immunoglobulins in membrane solution according to the analysis by electrophoresis [25].

As some patients with DDD also develop extrarenal manifestations such as ocular drusen, acquired partial lipodystrophy (APL), and diabetes mellitus type 1, DDD was once regarded as a glomerular disease associated with metabolic disorders [26]. Ocular drusen are whitish-yellow deposits of lipoproteins within the Bruch membrane beneath the retinal pigment epithelium, and complement complexes such as C5b-9 were identified in drusen associated with aging and other glomerulonephritis [27]. APL is a condition with permanent loss of adipose tissue from face and upper body, and often accompanied by low serum $\mathrm{C} 3$ levels and the presence of $\mathrm{C} 3 \mathrm{NeF}$. Adipose tissue produces some CRFs, and the activated complement pathway contributes to the deposition of complement components, resulting in the destruction of adipocytes in APL [28]. These disease associations suggested that a subset of DDD was mediated by systemic complement dysregulation.

Dysregulation of the alternative complement pathway in DDD was established by the detection of complement components in the glomeruli in situ and auto-antibodies in the serum. Complement component 3 nephritic factor (C3NeF), an auto-antibody to $\mathrm{C} 3$ convertase which was originally identified in the serum of cases with hypocomplementemic glomerulonephritis by quantitating C3 breakdown using an immunoprecipitation method [29], is detected in the serum in approximately $80 \%$ of cases with DDD [30]. Moreover, using mass spectrometry in the glomeruli of DDD, Sethi and co-workers could not detect CFB components despite the presence of alternative pathway component (C3), terminal complement complex (C5b-9), and its two fluid phase regulators: clusterin and vitronectin [31]. This suggests that the major site of alternative complement activation in DDD is in the fluid phase and subsequent inactive complement complex accumulates in the glomeruli.

\section{Mechanism of complement dysregulation in C3 glomerulopathy}

Excessive activation of the alternative complement pathway and amplification of $\mathrm{C} 3 \mathrm{~b}$ due to an inherited defect and/or acquired dysfunction of CRFs is considered to be the pathogenesis of C3G (Fig. 1) [23, 30]. By genetic analysis, several mutations including those in CFH, CFHR, CFI, MCP, C3, and CFB have been identified in patients with C3G [32-38]. The mutations in CRFs lead to loss of

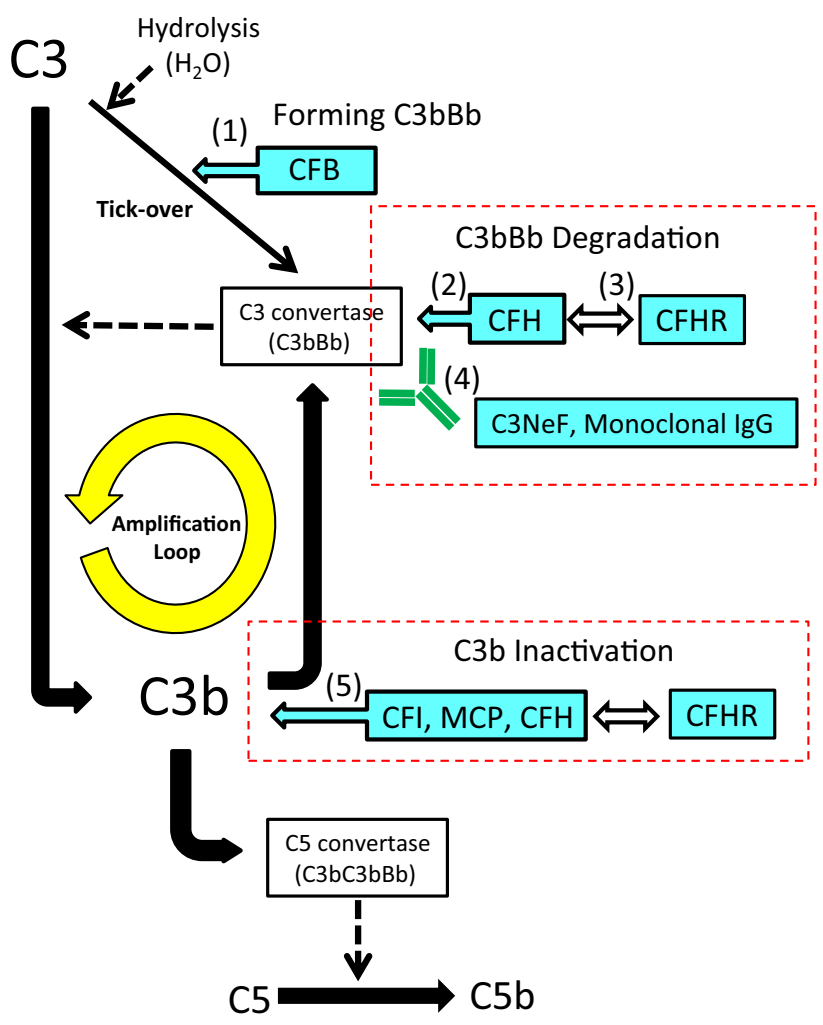

Fig. 1 Schema illustrates the complement cascade and CRFs of the alternative pathway in $\mathrm{C} 3 \mathrm{G}$. The key events in $\mathrm{C} 3 \mathrm{G}$ in this cascade include abnormal amplification of $\mathrm{C} 3 \mathrm{~b}$ production by activation of $\mathrm{C} 3$ to $\mathrm{C} 3 \mathrm{~b}$ through the following pathways. (1) Accelerated forming $\mathrm{C} 3 \mathrm{bBb}$ by $\mathrm{CFB}$ through gain of function. Activation of $\mathrm{C} 3 \mathrm{~b}$ convertase by (2) dysfunction of $\mathrm{CFH}$ which degrades $\mathrm{C} 3 \mathrm{bBb}$, (3) enhancing $\mathrm{CFH}$ deregulation by dysfunction of CFHR, or (4) production of $\mathrm{C} 3 \mathrm{NeF}$ which inhibits the degradation of $\mathrm{C} 3 \mathrm{bBb}$. (5) Suppression of $\mathrm{C} 3 \mathrm{~b}$ inactivation by $\mathrm{CFH} / \mathrm{CFI} / \mathrm{MCP} / \mathrm{CFHR}$ also amplifies $\mathrm{C} 3 \mathrm{~b}$ activation. This dysregulation of CRFs may be caused not only by inherited mutations in the genes responsible for these factors but also in acquired factors such as auto-antibodies for CRFs and $\mathrm{C} 3 \mathrm{NeF}$. $C F H$ complement factor $\mathrm{H}, C F I$ complement factor I, CFHR complement factor $\mathrm{H}$-related proteins, $M C P$ membrane cofactor protein, $C F B$ complement factor B, $\mathrm{C} 3 \mathrm{NeF}$ complement component 3 nephritic factor

function in $\mathrm{CFH}, \mathrm{CFI}$, and $\mathrm{MCP}$ or gain of function in $\mathrm{C} 3$ and $\mathrm{CFB}$, resulting in overactivation of the alternative complement pathway.

Acquired factors also promote $\mathrm{C} 3 \mathrm{~b}$ amplification. As mentioned above, $\mathrm{C} 3 \mathrm{NeF}$ is a well-known auto-antibody against the $\mathrm{C} 3$ convertase $(\mathrm{C} 3 \mathrm{bBb})$ that cleaves $\mathrm{C} 3$ into $\mathrm{C} 3 \mathrm{a}$ and $\mathrm{C} 3 \mathrm{~b}$. $\mathrm{C} 3 \mathrm{NeF}$ stabilizes $\mathrm{C} 3 \mathrm{bBb}$ and prevents the inhibitory actions of CRFs, resulting in uncontrolled $\mathrm{C} 3$ activation and low serum C3 levels [29]. However, because $\mathrm{C} 3 \mathrm{NeF}$ production is also found in other types of glomerular diseases and even in healthy individuals [39, 40], additional factors such as infections may trigger $\mathrm{C} 3 \mathrm{NeF}$ activation involved in the development of $\mathrm{C} 3 \mathrm{G}$.

In addition to $\mathrm{C} 3 \mathrm{NeF}$, hyper-production of monoclonal immunoglobulins (MIGs) that attack CRFs in 
hematological disorders underlies $\mathrm{C} 3 \mathrm{G}$ as another acquired factor. The glomerulonephritis associated with monoclonal gammopathy generally reveals MPGN by LM and C3 deposition with or without immunoglobulins by IF [41-44]. MIGs potentially activate the classical pathway directly or amplify the alternative complement pathway, depending on the function of the aberrantly synthesized MIGs [41]. Because mass spectrometry for glomerular tissue in $\mathrm{C} 3 \mathrm{G}$ cases associated with monoclonal gammopathy identified components of the alternative complement pathway in the glomeruli [42], and an anti-CFH antibody or $\mathrm{C} 3 \mathrm{NeF}$ was detected occasionally in the serum [42, 43], MIGs may act as auto-antibodies to protect degradation of $\mathrm{C} 3$ convertase, which finally activates $\mathrm{C} 3$ amplification loop (Fig. 1). One study analyzing 14 adult cases with DDD found monoclonal gammopathy of undetermined significance (MGUS) in $71 \%$ of them [43]. Thus, monoclonal gammopathy needs to be considered as a possible cause of C3G.

\section{Differences in alternative complement dysregulation between DDD and C3GN}

Although both DDD and C3GN are driven similarly by alternative complement dysregulation, the distinct pathophysiological mechanisms underlying each disease are still unknown. Zhang et al. reported higher $\mathrm{C} 3 \mathrm{NeF}$ activity in DDD than in C3GN, whereas soluble C5b-9 was higher in C3GN than in DDD [45]. Medjeral-Thomas et al. demonstrated that DDD presented more crescentic glomerulonephritis, at younger ages, lower serum C3 levels, and with greater predisposition to end-stage renal disease (ESRD) compared with C3GN [46]. These data suggest that DDD can be caused by earlier components dysregulated at C3 levels, whereas dysregulation in C3GN occurs in the late/terminal components of the alternative complement pathway. The different mechanisms between these two diseases may explain the more aggressive course in DDD than in $\mathrm{C} 3 \mathrm{GN}$.

\section{Current detection of alternative complement dysregulation in C3 glomerulopathy}

Practically, the inherited and/or acquired defects behind alternative complement pathway dysregulation have been identified only in a subset of patients with C3G. Servais et al. reported $\mathrm{CFH}$, CFI, or MCP mutations in $17.2 \%$ of cases with DDD and in $19.6 \%$ of those with C3GN [32], suggesting that the majority of $\mathrm{C} 3 \mathrm{G}$ cases do not possess genetic mutations in CRFs. In addition, $\mathrm{C} 3 \mathrm{NeF}$ is not detected in approximately $20 \%$ of cases with DDD and in more than half with $\mathrm{C} 3 \mathrm{GN}$ [32].

Based on the pathogenesis assumed in this disease, biochemical analysis for the alternative complement pathway is desirable to diagnose C3G [47]. It includes functional analysis based on hemolytic assays, quantification of complement components and CRFs, and measurement of complement activation markers such as $\mathrm{C} 3$ decay products and soluble C5b-9 [47]. These technologies will hopefully be available for every patient with predominant C3 deposition in the glomeruli.

\section{Alternative complement dysregulation in animal models}

A causal relationship between genetic abnormalities in CRFs and glomerular pathology has been demonstrated in animal models with genetic defects in CRFs. In CFH-deficient piglets and mice, activation of the alternative complement pathway resulted in low serum C3 levels [48-50]. In these models, glomeruli showed the MPGN pattern with linear C3 and subendothelial/intramembranous deposits, which correspond to human C3G. Such unique models may provide further understanding of the mechanisms of $\mathrm{C} 3$ deposition and lead to potential therapies for C3G.

\section{Clinical features and prognosis in $\mathrm{C3}$ glomerulopathy}

Clinically, most of the cases with $\mathrm{C} 3 \mathrm{G}$ present proteinuria and hematuria [46]. The cases of $6.9 \%$ in DDD and $16.1 \%$ of C3GN present nephrotic syndrome [32]. Low serum C3 levels are found in 59-79\% of DDD and 40-48\% of C3GN $[32,46]$. DDD is often diagnosed in childhood, whereas C3GN is usually developed at older age than DDD [46].

The long-term renal prognosis of $\mathrm{C} 3 \mathrm{G}$ is generally unfavorable. It was reported that $47 \%$ of 17 patients with DDD and $23 \%$ of 53 patients with C3GN progressed to ESRD during a median follow-up period of 28 months [46]. In addition, the recurrence of $\mathrm{C} 3 \mathrm{G}$ after renal transplantation occurs frequently resulting in graft loss: $50 \%$ in DDD, 43\% in C3GN [46].

\section{Histopathology of C3 glomerulopathy}

C3G reveal various histological patterns of glomerular injury by LM, including mesangial proliferative, diffuse endocapillary proliferative, and crescentic glomerulonephritis $[7,19,20]$. This indicates that discrimination of $\mathrm{C} 3 \mathrm{GN}$ and DDD is difficult by LM, except in cases with the typical features of DDD such as intensely Periodic acid-Schiff (PAS) staining positive, ribbon-like intramembranous deposits with thickened GBM $[13,51]$. These unique deposits also show lack of methenamine silver staining (Fig. 2), fuchsinophilic (red) in trichrome staining, dark blue with toluidine blue, and positive for the thioflavin $\mathrm{T}[51,52]$.

IF findings of $\mathrm{C} 3 \mathrm{G}$ were defined initially as isolated $\mathrm{C} 3$ deposition [1], but the deposition of $\mathrm{C} 3$ is not always 
Fig. 2 Representative glomerular features of DDD and C3GN by light microscopy (LM) and electron microscopy (EM). DDD by LM (a) shows thickened glomerular basement membrane (GBM) stained negatively with methenamine silver, giving pink color with hematoxylin. In C3GN, LM (b) reveals irregular GBM with double contours stained on the background of mesangial proliferation. By EM, a highly electron-dense deposition replaces the lamina densa of GBM (c) in DDD, whereas C3GN shows thickened GBM with mottled and less osmiophilic deposits versus those of DDD (d)
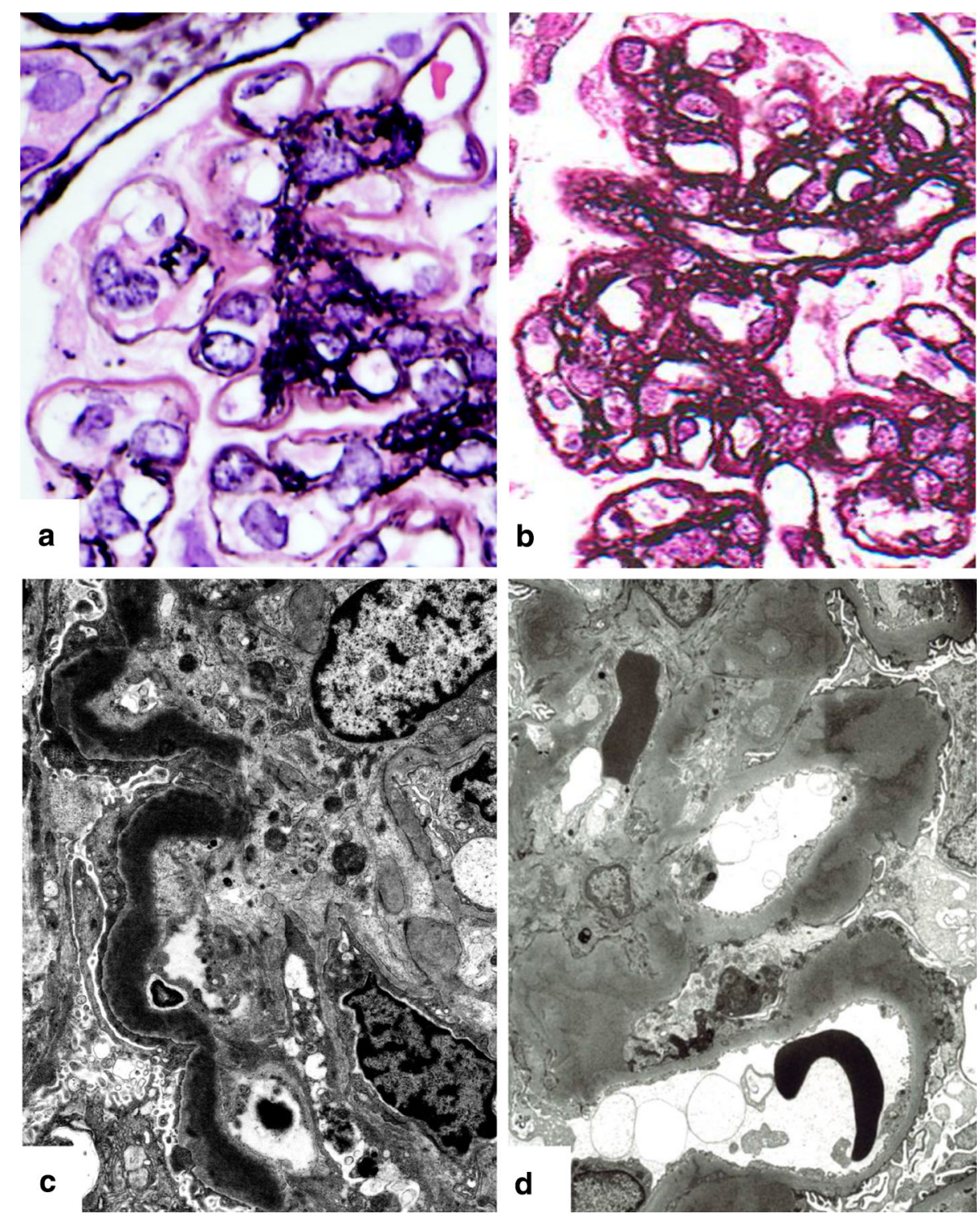

"isolated". According to the current consensus report, the term "isolated" was replaced by "dominant staining of C3 defined as at least two orders of C3 intensity greater than that of any other immune reactant" [6]. This extended definition was derived from the fact that $47.6 \%$ of DDD cases show various amounts of glomerular immunoglobulin deposits even though they are caused by alternative complement activation [21]. More studies are needed to explain the immunoglobulin depositions in DDD, particularly on the initial immune reaction that induces alternative complement dysregulation.

\section{Diagnostic dilemmas in C3 glomerulopathy}

The entity of $\mathrm{C} 3 \mathrm{G}$ is rational, but it still presents some diagnostic dilemmas in practice. Given that $\mathrm{C} 3 \mathrm{G}$ is defined by predominant glomerular C3 deposition (two orders greater than immunoglobulins), other glomerulonephritis types, particularly those that are immune complex-mediated, occasionally fit this criterion, too. Table 1 summarizes the clinical and histopathological features of DDD [5, 32, 46, 52-56], C3GN [5, 32, 46, 52, 57], and PIGN [52, 58-61].

\section{C3G versus PIGN}

PIGN is a distinct immune complex-mediated glomerulonephritis caused by antibodies against infectious microbes [58]. Because diseases in this category generally have favorable prognoses, they should be distinguished from $\mathrm{C} 3 \mathrm{G}$. The difficulty with the differential diagnosis in this case may be explained by the following considerations. First, PIGN is an immune complex-mediated glomerulonephritis, but it sometimes shows isolated C3 deposition 


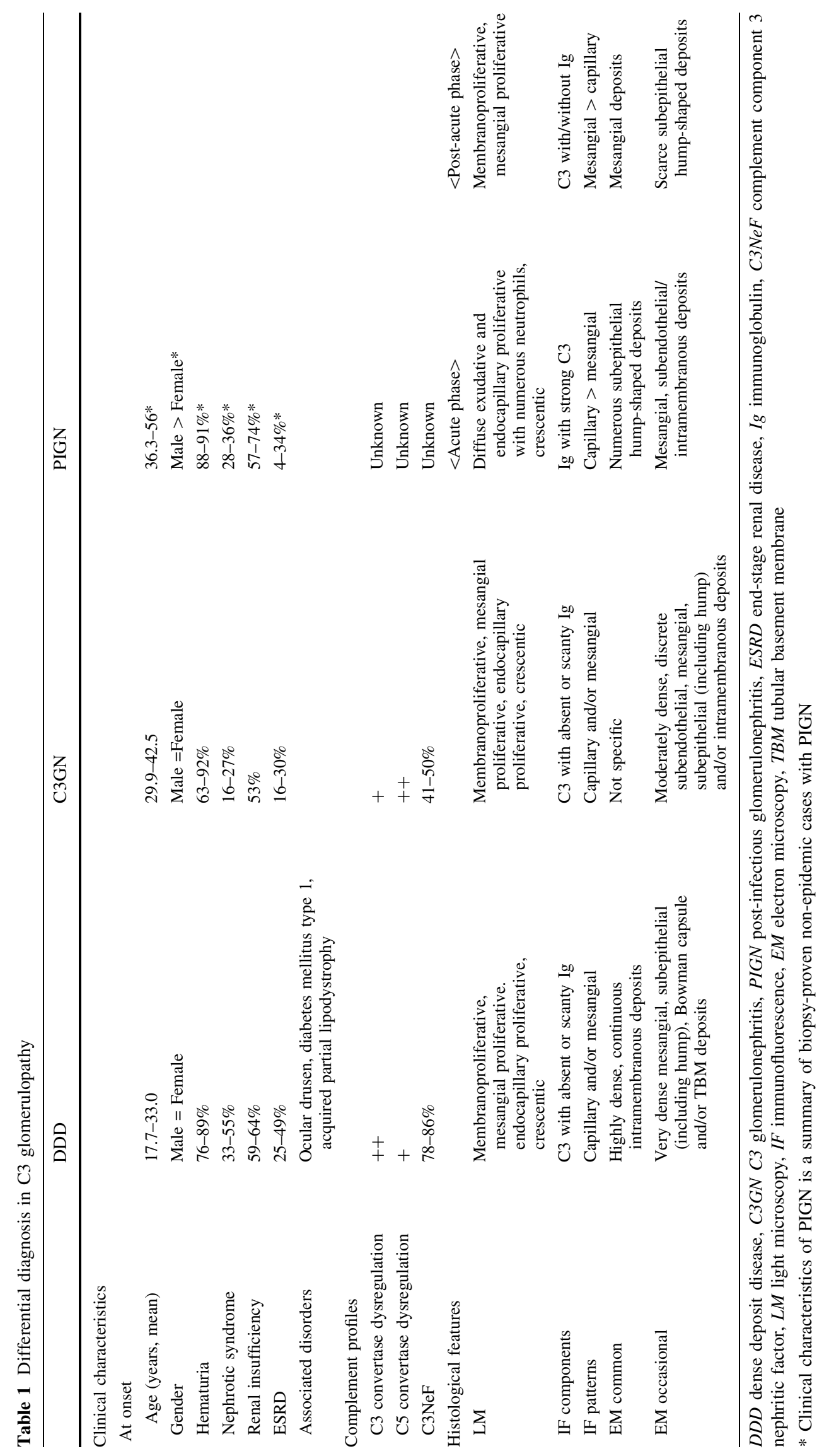


without immunoglobulins, particularly during the postacute phase [9]. The mechanism of isolated C3 deposition during the late phase of PIGN has been suggested to be persistent C3 amplification, while the deposition of $\mathrm{IgG}$ drops to undetectable levels [62]. Second, the presence of the "hump", the characteristic deposition of PIGN, is not specific but is often seen in other glomerulonephritis types including MPGN and C3G [7], and it disappears during the later phase of PIGN [63]. Third, C3G occasionally shows endocapillary proliferative glomerulonephritis similar to PIGN [6, 7, 46, 57]. Conversely, PIGN can show expansion of the lobules, hypercellularity of the tuft, and thickening of the glomerular capillary walls mimicking MPGN [60]. Finally, some cases with PIGN reveal prolonged proteinuria and low serum C3 levels that clinically and pathologically represent chronic glomerulonephritis similar to C3G [9]. The IF pattern alone is insufficient to discriminate whether a faint deposit of $\mathrm{IgG}$ is an immune complex or not. In this regard, glomerular staining of $\mathrm{C} 4 \mathrm{~d}$, a byproduct of activation of the classical and lectin pathways, may be useful for the identification of an immune complex-mediated mechanism [64].

Interestingly, recent reports suggested the transformation of PIGN to $\mathrm{C} 3 \mathrm{G}$ by repeat biopsies [65-68]. In this context, there are several possibilities, including (1) the transformation of PIGN to $\mathrm{C} 3 \mathrm{G}$, (2) similar appearances of early lesions of $\mathrm{C} 3 \mathrm{G}$ and PIGN, and (3) initiation of $\mathrm{C} 3 \mathrm{G}$ by streptococcal infection. Sethi et al. described that most of the cases with biopsy-proven PIGN presenting persistent hematuria and proteinuria had underlying defects with genetic mutations and/or auto-antibodies affecting regulation of the alternative complement pathway [9]. In addition, several reports have demonstrated the presence of nephritis-associated plasmin receptor (known as NAPlr), a nephritogenic antigen for post-streptococcal acute glomerulonephritis, in cases with C3G [65, 69, 70]. These findings indicate that glomerular injuries initiated by infection may transfer to $\mathrm{C} 3 \mathrm{G}$ by switching activation of the alternative complement pathway. It may be surmised that $\mathrm{C} 3 \mathrm{G}$ is initiated by heterogeneous insults, leading to a final common pathway of alternative complement dysregulation. Clearly, more studies and case observations are necessary to determine the mechanism of $\mathrm{C} 3 \mathrm{G}$ and to identify critical differential tools to discriminate it from PIGN.

\section{$D D D$ versus $C 3 G N$}

The distinction between DDD and C3GN is also sometimes difficult [6, 10]. Patterns of IF in these two diseases are often similar and provide little basis for discrimination. In fact, glomerulonephritis with "dominant staining of C3 defined as at least two orders of C3 intensity greater than that of any other immune reactant" without DDD-like deposits by EM is automatically classified as C3GN. Electron-dense deposits of $\mathrm{C} 3 \mathrm{GN}$ are generally less dense, less well defined, and more amorphous than those of DDD. In addition, these deposits are found in subendothelial and mesangial regions as well as occasionally in intramembranous and subepithelial regions as seen in DDD [7]. Ultimately, the density and pattern of the intramembranous dense deposits are the critical differences between C3GN and DDD. In this regard, we may diagnose atypical or incipient DDD as C3GN when it lacks DDD-like deposits. The reason for the different density and pattern of electrondense deposits remains unclear. One of the reasons may be speculated that components other than complement system can exist in depositions in DDD, such as previously suggested metabolic substances. Although it is still unknown whether $\mathrm{C} 3 \mathrm{GN}$ transforms to DDD or vice versa, a few reports have described that the early pathology of recurrent DDD in renal transplantation, showing isolated C3 deposition without DDD-like EM features which was corresponding to C3GN [71, 72], developed into typical DDD in repeat biopsies [71]. If some cases of DDD and C3GN are in different stages of the same disease, there should be intermediate cases that are more difficult to be diagnosed (Fig. 3). It may be possible that undetermined cases of $\mathrm{C} 3 \mathrm{G}$ represent different stages of the same disease, and it would be better to incorporate DDD and C3GN into the same category of "alternative complement-mediated glomerulonephritis" on the basis of common pathogenesis. Apparently, molecular or genetic markers to discriminate DDD and C3GN are necessary if these two diseases have different pathogenesis. The current concept of $\mathrm{C} 3 \mathrm{G}$ is summarized in Fig. 4, and the pathogenesis of this disease can be a base of the therapies.

\section{Therapeutic prospects for C3 glomerulopathy}

In current practice, the main treatments for $\mathrm{C} 3 \mathrm{G}$ are immunosuppressive and supportive therapies. $\mathrm{C} 3 \mathrm{G}$ is a heterogeneous disease entity with various pathogenic mechanisms that commonly cause alternative complement dysregulation [30]. Whatever the causative factors are, immunosuppressive therapies are appropriate because of the inflammatory nature of this glomerular disease. In addition, immunosuppression may also be effective in $\mathrm{C} 3 \mathrm{G}$ cases associated with auto-antibodies for complement components or CRFs such as $\mathrm{C} 3 \mathrm{NeF}$. As immunosuppressant drugs, corticosteroids [73, 74], cyclophosphamide [75, 76], mycophenolate mofetil (MMF) [77], and rituximab [78, 79] have been used for $\mathrm{C} 3 \mathrm{G}$. Plasma exchange can benefit patients with $\mathrm{C} 3 \mathrm{G}$ by removing auto-antibodies or mutant proteins and replacing normal CRFs [80-83]. However, the efficacy of such immune modulations and 
Fig. 3 Pediatric case with low serum C3 levels over five years showing the MPGN pattern by light microscopy (a Periodic acid-Schiff stain and $\mathbf{b}$ Periodic acid-methenamine silver stain) with isolated granular C3 deposition by immunofluorescence (middle panels). Electron microscopy shows mesangial and intramembranous deposits that are not very dense (c), as usually seen in DDD (Fig. 1). In a portion, intramembranous continuous deposition with moderate density was seen (d). This case was presented at international conferences, and there were inconsistent diagnoses among renal pathologists. Abnormalities of complement factors are under investigation
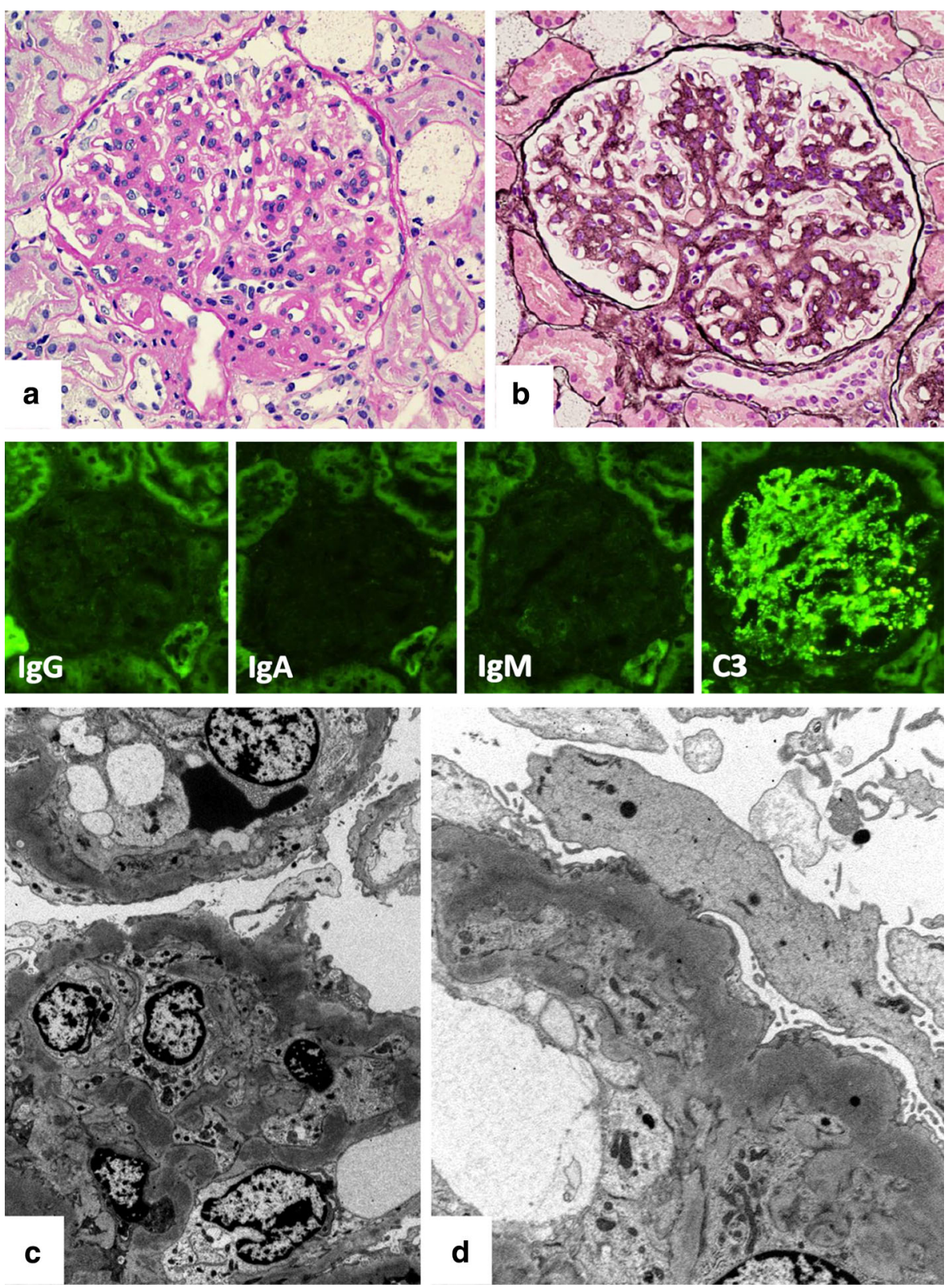

conventional therapies has been limited and direct blocking of C3 amplification loop is needed for C3G. Although the mechanism is not related to remedy of complement dysregulation, inhibitors of renin-angiontensin system are the only recommended agents for $\mathrm{C} 3 \mathrm{G}$ due to the association with better renal survival [32].

Eculizumab can be a modern therapy against $\mathrm{C} 3 \mathrm{G}$ that acts by inhibiting the alternative complement overactivation. This new agent is a humanized monoclonal anti-C5 antibody and prevents $\mathrm{C} 5$ cleavage into $\mathrm{C} 5 \mathrm{a}$, a chemotactic agent and an anaphylatoxin, and $\mathrm{C} 5 \mathrm{~b}$, one of the components of membrane attack complex (C5b-9) [84]. Several cases of C3G treated with eculizumab have been reported recently, but its efficacy has been limited only in a subset of them
$[79,85-88]$. One of the reasons for inconsistent efficacy is speculated that eculizumab basically blocks the terminal pathway by inhibiting the formation of membrane attack complex, and might be ineffective particularly for the patients with $\mathrm{C} 3 \mathrm{G}$ more involved by activation of the upper pathway. On the other hand, some cases with $\mathrm{C} 3 \mathrm{G}$ treated with eculizumab revealed the reduction of glomerular $\mathrm{C} 3$ deposition, suggesting that C5a blocking may lead to resolving the upper pathway activation through the decrease of glomerular inflammation in such cases. In addition to $\mathrm{C} 3 \mathrm{NeF}$ synthesized by autoimmune mechanisms, MIGs overproduced in hematological disorders attack CRFs, leading to C3G [41]. In this case, therapy for monoclonal gammopathy is a principle to halt the amplification loop. 


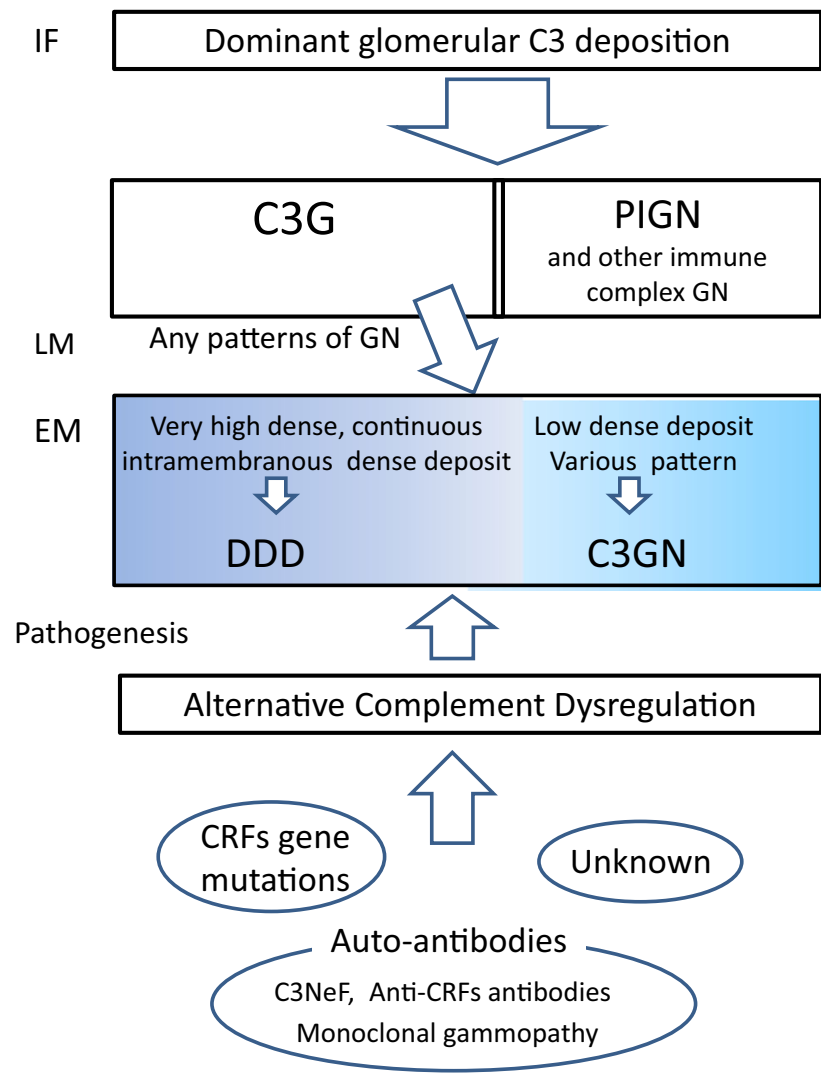

Fig. 4 Current status of C3G. Glomerular deposition of predominant $\mathrm{C} 3$ suggests the possibility of $\mathrm{C} 3 \mathrm{G}$, which needs to be discriminated from immune complex-mediated GN. By LM, C3G shows various glomerular patterns. DDD and $\mathrm{C} 3 \mathrm{GN}$ are discriminated by EM features, but a clear distinction to differentiate these two diseases is often difficult. Alternative complement dysregulation is an ultimate definition of $\mathrm{C} 3 \mathrm{G}$, and several factors may amplify alternative complement activation such as CRF gene mutations causing loss or gain of function, and auto-antibodies such as $\mathrm{C} 3 \mathrm{NeF}$ stabilizing $\mathrm{C} 3$ convertase. In most cases, however, the cause remains unknown. Monoclonal immunoglobulin occasionally functions as an autoantibody. IF immunofluorescence, $L M$ light microscopy, $E M$ electron microscopy, $C 3 G \mathrm{C} 3$ glomerulopathy, $P I G N$ post-infectious glomerulonephritis, $G N$ glomerulonephritis, $D D D$ dense deposit disease, $C 3 G N$ C3 glomerulonephritis, CRFs complement regulatory factors, $\mathrm{C} 3 \mathrm{NeF}$ complement component 3 nephritic factor

At present, there are still many missing pieces that must be assembled to determine pathophysiology-based therapies for $\mathrm{C} 3 \mathrm{G}$, and further investigations are certainly warranted.

\section{Conclusions}

$\mathrm{C} 3 \mathrm{G}$ is a novel and rational disease classification based on the pathogenesis of the dysregulated alternative complement pathway. However, it is still a tentative category including glomerular diseases of variable morphologies, stages, and pathophysiologies, resulting in some diagnostic dilemmas.
We need to solve these dilemmas to bring the promise of rational diagnosis and pathogenesis-based therapies to the bedside.

Acknowledgements We thank Drs. Riku Hamada, Wataru Kubota in Tokyo Metropolitan Children's Medical Center for providing the case shown in Fig. 3. English edition was done by Dr. Matthew Higgins and at least two professional editors, and all are native speakers of English. For a certificate, see http://www.textcheck.com/certificate/rUaCpl.

\section{Compliance with ethical standards}

Conflict of interest The authors have declared that no conflicts of interest exist.

Open Access This article is distributed under the terms of the Creative Commons Attribution 4.0 International License (http://crea tivecommons.org/licenses/by/4.0/), which permits use, duplication, adaptation, distribution and reproduction in any medium or format, as long as you give appropriate credit to the original author(s) and the source, provide a link to the Creative Commons license and indicate if changes were made.

\section{References}

1. Fakhouri F, Fremeaux-Bacchi V, Noel LH, Cook HT, Pickering MC. C3 glomerulopathy: a new classification. Nat Rev Nephrol. 2010;6:494-9.

2. Barbour TD, Ruseva MM, Pickering MC. Update on C3 glomerulopathy. Nephrol Dial Transplant. 2016;31:717-25.

3. Sethi S, Fervenza FC, Zhang Y, Nasr SH, Leung N, Vrana J, et al. Proliferative glomerulonephritis secondary to dysfunction of the alternative pathway of complement. Clin J Am Soc Nephrol. 2011;6:1009-17.

4. Barbour TD, Pickering MC, Terence Cook H. Dense deposit disease and C3 glomerulopathy. Semin Nephrol. 2013;33:493-507.

5. Thomas S, Ranganathan D, Francis L, Madhan K, John GT. Current concepts in C3 glomerulopathy. Indian J Nephrol. 2014;24:339-48.

6. Pickering MC, D'Agati VD, Nester CM, Smith RJ, Haas M, Appel GB, et al. C3 glomerulopathy: consensus report. Kidney Int. 2013;84:1079-89.

7. Cook HT, Pickering MC. Histopathology of MPGN and C3 glomerulopathies. Nat Rev Nephrol. 2015;11:14-22.

8. Sethi S. Etiology-based diagnostic approach to proliferative glomerulonephritis. Am J Kidney Dis. 2014;63:561-6.

9. Sethi S, Fervenza FC, Zhang Y, Zand L, Meyer NC, Borsa N, et al. Atypical postinfectious glomerulonephritis is associated with abnormalities in the alternative pathway of complement. Kidney Int. 2013;83:293-9.

10. Sethi S, Fervenza FC, Smith RJ, Haas M. Overlap of ultrastructural findings in $\mathrm{C} 3$ glomerulonephritis and dense deposit disease. Kidney Int. 2015;88:1449-50.

11. Cameron JS, Glasgow EF, Ogg CS, White RH. Membranoproliferative glomerulonephritis and persistent hypocomplementaemia. Br Med J. 1970;4:7-14.

12. West CD. Pathogenesis and approaches to therapy of membranoproliferative glomerulonephritis. Kidney Int. 1976;9:1-7.

13. Habib R, Gubler MC, Loirat C, Maiz HB, Levy M. Dense deposit disease: a variant of membranoproliferative glomerulonephritis. Kidney Int. 1975;7:204-15.

14. Burkholder PM, Marchand A, Krueger RP. Mixed membranous and proliferative glomerulonephritis. A correlative light, 
immunofluorescence, and electron microscopic study. Lab Invest. 1970;23:459-79.

15. Strife CF, McEnery PT, McAdams AJ, West CD. Membranoproliferative glomerulonephritis with disruption of the glomerular basement membrane. Clin Nephrol. 1977;7:65-72.

16. Anders D, Agricola B, Sippel M, Thoenes W. Basement membrane changes in membranoproliferative glomerulonephritis. II. Characterization of a third type by silver impregnation of ultra thin sections. Virchows Arch A Pathol Anat Histol. 1977;376:1-19.

17. Habib R, Kleinknecht C, Gubler MC, Levy M. Idiopathic membranoproliferative glomerulonephritis in children. Report of 105 cases. Clin Nephrol. 1973;1:194-214.

18. Sibley RK, Kim Y. Dense intramembranous deposit disease: new pathologic features. Kidney Int. 1984;25:660-70.

19. Walker PD, Ferrario F, Joh K, Bonsib SM. Dense deposit disease is not a membranoproliferative glomerulonephritis. Mod Pathol. 2007;20:605-16.

20. Joh K, Aizawa S, Matsuyama N, Yamaguchi Y, Kitajima T, Sakai $\mathrm{O}$, et al. Morphologic variations of dense deposit disease: light and electron microscopic, immunohistochemical and clinical findings in 10 patients. Acta Pathol Jpn. 1993;43:552-65.

21. Hou J, Markowitz GS, Bomback AS, Appel GB, Herlitz LC, Barry Stokes M, et al. Toward a working definition of C3 glomerulopathy by immunofluorescence. Kidney Int. 2014;85:450-6.

22. Ricklin D, Hajishengallis G, Yang K, Lambris JD. Complement: a key system for immune surveillance and homeostasis. Nat Immunol. 2010;11:785-97.

23. Thurman JM. Complement in kidney disease: core curriculum 2015. Am J Kidney Dis. 2015;65:156-68.

24. Berger J, Galle P. Dense Deposits within the Basal Membranes of the Kidney. Optical and Electron Microscopic Study. Presse Med. 1963;71:2351-4.

25. Galle P, Mahieu P. Electron dense alteration of kidney basement membranes. A renal lesion specific of a systemic disease. Am J Med. 1975;58:749-64.

26. Appel GB, Cook HT, Hageman G, Jennette JC, Kashgarian M, Kirschfink M, et al. Membranoproliferative glomerulonephritis type II (dense deposit disease): an update. J Am Soc Nephrol. 2005;16:1392-403.

27. Mullins RF, Aptsiauri N, Hageman GS. Structure and composition of drusen associated with glomerulonephritis: implications for the role of complement activation in drusen biogenesis. Eye (Lond). 2001;15:390-5.

28. Mathieson PW, Peters DK. Lipodystrophy in MCGN type II: the clue to links between the adipocyte and the complement system. Nephrol Dial Transplant. 1997;12:1804-6.

29. Spitzer RE, Vallota EH, Forristal J, Sudora E, Stitzel A, Davis NC, et al. Serum C'3 lytic system in patients with glomerulonephritis. Science. 1969;164:436-7.

30. Bomback AS, Appel GB. Pathogenesis of the C3 glomerulopathies and reclassification of MPGN. Nat Rev Nephrol. 2012;8:634-42.

31. Sethi S, Gamez JD, Vrana JA, Theis JD, Bergen HR 3rd, Zipfel $\mathrm{PF}$, et al. Glomeruli of Dense Deposit Disease contain components of the alternative and terminal complement pathway. Kidney Int. 2009;75:952-60.

32. Servais A, Noel LH, Roumenina LT, Le Quintrec M, Ngo S, Dragon-Durey MA, et al. Acquired and genetic complement abnormalities play a critical role in dense deposit disease and other C3 glomerulopathies. Kidney Int. 2012;82:454-64.

33. Servais A, Fremeaux-Bacchi V, Lequintrec M, Salomon R, Blouin J, Knebelmann B, et al. Primary glomerulonephritis with isolated C3 deposits: a new entity which shares common genetic risk factors with haemolytic uraemic syndrome. J Med Genet. 2007;44:193-9.
34. Gale DP, de Jorge EG, Cook HT, Martinez-Barricarte R, Hadjisavvas A, McLean AG, et al. Identification of a mutation in complement factor $\mathrm{H}$-related protein 5 in patients of Cypriot origin with glomerulonephritis. Lancet. 2010;376:794-801.

35. Athanasiou Y, Voskarides K, Gale DP, Damianou L, Patsias C, Zavros M, et al. Familial C3 glomerulopathy associated with CFHR5 mutations: clinical characteristics of 91 patients in 16 pedigrees. Clin J Am Soc Nephrol. 2011;6:1436-46.

36. Martínez-Barricarte R, Heurich M, Valdes-Cañedo F, VazquezMartul E, Torreira E, Montes T, et al. Human C3 mutation reveals a mechanism of dense deposit disease pathogenesis and provides insights into complement activation and regulation. J Clin Invest. 2010;120:3702-12.

37. Imamura $H$, Konomoto $T$, Tanaka $E$, Hisano $S$, Yoshida $Y$, Fujimura Y, et al. Familial C3 glomerulonephritis associated with mutations in the gene for complement factor B. Nephrol Dial Transplant. 2015;30:862-4.

38. Zipfel PF, Skerka C, Chen Q, Wiech T, Goodship T, Johnson S, et al. The role of complement in $\mathrm{C} 3$ glomerulopathy. Mol Immunol. 2015;67:21-30.

39. Fremeaux-Bacchi V, Weiss L, Demouchy C, May A, Palomera S, Kazatchkine MD. Hypocomplementaemia of poststreptococcal acute glomerulonephritis is associated with $\mathrm{C} 3$ nephritic factor (C3NeF) IgG autoantibody activity. Nephrol Dial Transplant. 1994;9:1747-50.

40. Gewurz AT, Imherr SM, Strauss S, Gewurz H, Mold C. C3 nephritic factor and hypocomplementaemia in a clinically healthy individual. Clin Exp Immunol. 1983;54:253-8.

41. Sethi S, Rajkumar SV. Monoclonal gammopathy-associated proliferative glomerulonephritis. Mayo Clin Proc. 2013;88:1284-93.

42. Zand L, Kattah A, Fervenza FC, Smith RJ, Nasr SH, Zhang Y, et al. C3 glomerulonephritis associated with monoclonal gammopathy: a case series. Am J Kidney Dis. 2013;62:506-14.

43. Sethi S, Sukov WR, Zhang Y, Fervenza FC, Lager DJ, Miller DV, et al. Dense deposit disease associated with monoclonal gammopathy of undetermined significance. Am J Kidney Dis. 2010;56:977-82.

44. Bridoux F, Desport E, Fremeaux-Bacchi V, Chong CF, Gombert $\mathrm{JM}$, Lacombe C, et al. Glomerulonephritis with isolated C3 deposits and monoclonal gammopathy: a fortuitous association? Clin J Am Soc Nephrol. 2011;6:2165-74.

45. Zhang Y, Nester CM, Martin B, Skjoedt MO, Meyer NC, Shao D, et al. Defining the complement biomarker profile of $\mathrm{C} 3$ glomerulopathy. Clin J Am Soc Nephrol. 2014;9:1876-82.

46. Medjeral-Thomas NR, O'Shaughnessy MM, O'Regan JA, Traynor C, Flanagan M, Wong L, et al. C3 glomerulopathy: clinicopathologic features and predictors of outcome. Clin J Am Soc Nephrol. 2014;9:46-53.

47. Angioi A, Fervenza FC, Sethi S, Zhang Y, Smith RJ, Murray D, et al. Diagnosis of complement alternative pathway disorders. Kidney Int. 2016;89:278-88.

48. Jansen JH, Hogasen K, Mollnes TE. Extensive complement activation in hereditary porcine membranoproliferative glomerulonephritis type II (porcine dense deposit disease). Am J Pathol. 1993;143:1356-65.

49. Hogasen K, Jansen JH, Mollnes TE, Hovdenes J, Harboe M. Hereditary porcine membranoproliferative glomerulonephritis type II is caused by factor $\mathrm{H}$ deficiency. $\mathrm{J}$ Clin Invest. 1995;95:1054-61.

50. Pickering MC, Cook HT, Warren J, Bygrave AE, Moss J, Walport MJ, et al. Uncontrolled C3 activation causes membranoproliferative glomerulonephritis in mice deficient in complement factor H. Nat Genet. 2002;31:424-8.

51. Churg J, Duffy JL, Bernstein J. Identification of dense deposit disease: a report for the International Study of Kidney Diseases in Children. Arch Pathol Lab Med. 1979;103:67-72. 
52. Jennette JC, Olson JL, Silva FG, D'Agati VD. Heptinstall's Pathology of the Kidney. 7th ed. Philadelphia: Wolters Kluwer; 2015. p. 341-436.

53. Cameron JS, Turner DR, Heaton J, Williams DG, Ogg CS, Chantler $\mathrm{C}$, et al. Idiopathic mesangiocapillary glomerulonephritis. Comparison of types I and II in children and adults and long-term prognosis. Am J Med. 1983;74:175-92.

54. Nasr SH, Valeri AM, Appel GB, Sherwinter J, Stokes MB, Said SM, et al. Dense deposit disease: clinicopathologic study of 32 pediatric and adult patients. Clin J Am Soc Nephrol. 2009;4:22-32.

55. Zhang Y, Meyer NC, Wang K, Nishimura C, Frees K, Jones M, et al. Causes of alternative pathway dysregulation in dense deposit disease. Clin J Am Soc Nephrol. 2012;7:265-74.

56. Lu DF, Moon M, Lanning LD, McCarthy AM, Smith RJ. Clinical features and outcomes of 98 children and adults with dense deposit disease. Pediatr Nephrol. 2012;27:773-81.

57. Sethi S, Fervenza FC, Zhang Y, Zand L, Vrana JA, Nasr SH, et al. C3 glomerulonephritis: clinicopathological findings, complement abnormalities, glomerular proteomic profile, treatment, and follow-up. Kidney Int. 2012;82:465-73.

58. Kanjanabuch T, Kittikowit W, Eiam-Ong S. An update on acute postinfectious glomerulonephritis worldwide. Nat Rev Nephrol. 2009;5:259-69.

59. Nasr SH, Markowitz GS, Stokes MB, Said SM, Valeri AM, D'Agati VD. Acute postinfectious glomerulonephritis in the modern era: experience with 86 adults and review of the literature. Medicine (Baltimore). 2008;87:21-32.

60. Montseny JJ, Meyrier A, Kleinknecht D, Callard P. The current spectrum of infectious glomerulonephritis. Experience with 76 patients and review of the literature. Medicine (Baltimore). 1995;74:63-73.

61. Moroni G, Pozzi C, Quaglini S, Segagni S, Banfi G, Baroli A, et al. Long-term prognosis of diffuse proliferative glomerulonephritis associated with infection in adults. Nephrol Dial Transplant. 2002;17:1204-11.

62. Fish AJ, Herdman RC, Michael AF, Pickering RJ, Good RA. Epidemic acute glomerulonephritis associated with type 49 streptococcal pyoderma. II. Correlative study of light, immunofluorescent and electron microscopic findings. Am J Med. 1970;48:28-39.

63. Herdson PB, Jennings RB, Earle DP. Glomerular fine structure in poststreptococcal acute glomerulonephritis. Arch Pathol. 1966;81:117-28.

64. Sethi S, Nasr SH, De Vriese AS, Fervenza FC. C4d as a Diagnostic Tool in Proliferative GN. J Am Soc Nephrol. 2015;26:2852-9.

65. Suga K, Kondo S, Matsuura S, Kinoshita Y, Kitano E, Hatanaka $\mathrm{M}$, et al. A case of dense deposit disease associated with a group A streptococcal infection without the involvement of $\mathrm{C} 3 \mathrm{NeF}$ or complement factor $\mathrm{H}$ deficiency. Pediatr Nephrol. 2010;25:1547-50.

66. Vernon KA, Goicoechea de Jorge E, Hall AE, Fremeaux-Bacchi V, Aitman TJ, Cook HT, et al. Acute presentation and persistent glomerulonephritis following streptococcal infection in a patient with heterozygous complement factor $\mathrm{H}$-related protein 5 deficiency. Am J Kidney Dis. 2012;60:121-5.

67. Sandhu G, Bansal A, Ranade A, Jones J, Cortell S, Markowitz GS. C3 glomerulopathy masquerading as acute postinfectious glomerulonephritis. Am J Kidney Dis. 2012;60:1039-43.

68. Prasto J, Kaplan BS, Russo P, Chan E, Smith RJ, Meyers KE. Streptococcal infection as possible trigger for dense deposit disease (C3 glomerulopathy). Eur J Pediatr. 2014;173:767-72.

69. Sawanobori E, Umino A, Kanai H, Matsushita K, Iwasa S, Kitamura H, et al. A prolonged course of Group A streptococcusassociated nephritis: a mild case of dense deposit disease (DDD)? Clin Nephrol. 2009;71:703-7.
70. Okabe M, Tsuboi N, Yokoo T, Miyazaki Y, Utsunomiya Y, Hosoya T. A case of idiopathic membranoproliferative glomerulonephritis with a transient glomerular deposition of nephritis-associated plasmin receptor antigen. Clin Exp Nephrol. 2012;16:337-41.

71. Aita K, Ito S, Tanabe K, Toma H, Yamaguchi Y, Nagata M. Early recurrence of dense deposit disease with marked endocapillary proliferation after renal transplantation. Pathol Int. 2006;56:101-9.

72. Andresdottir MB, Assmann KJ, Hoitsma AJ, Koene RA, Wetzels JF. Renal transplantation in patients with dense deposit disease: morphological characteristics of recurrent disease and clinical outcome. Nephrol Dial Transplant. 1999;14:1723-31.

73. Tarshish P, Bernstein J, Tobin JN, Edelmann CM Jr. Treatment of mesangiocapillary glomerulonephritis with alternate-day prednisone-a report of the International Study of Kidney Disease in Children. Pediatr Nephrol. 1992;6:123-30.

74. Donadio JV Jr, Offord KP. Reassessment of treatment results in membranoproliferative glomerulonephritis, with emphasis on life-table analysis. Am J Kidney Dis. 1989;14:445-51.

75. Krmar RT, Holtback U, Linne T, Berg UB, Celsi G, Soderberg $\mathrm{MP}$, et al. Acute renal failure in dense deposit disease: complete recovery after combination therapy with immunosuppressant and plasma exchange. Clin Nephrol. 2011;75(Suppl 1):4-10.

76. Lien YH, Scott K. Long-term cyclophosphamide treatment for recurrent type I membranoproliferative glomerulonephritis after transplantation. Am J Kidney Dis. 2000;35:539-43.

77. Rabasco C, Cavero T, Roman E, Rojas-Rivera J, Olea T, Espinosa $\mathrm{M}$, et al. Effectiveness of mycophenolate mofetil in $\mathrm{C} 3$ glomerulonephritis. Kidney Int. 2015;88:1153-60.

78. Giaime P, Daniel L, Burtey S. Remission of C3 glomerulopathy with rituximab as only immunosuppressive therapy. Clin Nephrol. 2015;83:57-60.

79. Rousset-Rouviere C, Cailliez M, Garaix F, Bruno D, Laurent D, Tsimaratos M. Rituximab fails where eculizumab restores renal function in C3nef-related DDD. Pediatr Nephrol. 2014;29:1107-11.

80. Haffner K, Michelfelder S, Pohl M. Successful therapy of C3Nefpositive $\mathrm{C} 3$ glomerulopathy with plasma therapy and immunosuppression. Pediatr Nephrol. 2015;30:1951-9.

81. Kurtz KA, Schlueter AJ. Management of membranoproliferative glomerulonephritis type II with plasmapheresis. J Clin Apher. 2002;17:135-7.

82. Oberkircher OR, Enama M, West JC, Campbell P, Moran J. Regression of recurrent membranoproliferative glomerulonephritis type II in a transplanted kidney after plasmapheresis therapy. Transplant Proc. 1988;20:418-23.

83. McGinley E, Watkins R, McLay A, Boulton-Jones JM. Plasma exchange in the treatment of mesangiocapillary glomerulonephritis. Nephron. 1985;40:385-90.

84. Zuber J, Fakhouri F, Roumenina LT, Loirat C, Fremeaux-Bacchi V. Use of eculizumab for atypical haemolytic uraemic syndrome and C3 glomerulopathies. Nat Rev Nephrol. 2012;8:643-57.

85. Oosterveld MJ, Garrelfs MR, Hoppe B, Florquin S, Roelofs JJ, van den Heuvel LP, et al. Eculizumab in pediatric dense deposit disease. Clin J Am Soc Nephrol. 2015;10:1773-82.

86. Le Quintrec M, Lionet A, Kandel C, Bourdon F, Gnemmi V, Colombat $\mathrm{M}$, et al. Eculizumab for treatment of rapidly progressive C3 glomerulopathy. Am J Kidney Dis. 2015;65:484-9.

87. Herlitz LC, Bomback AS, Markowitz GS, Stokes MB, Smith RN, Colvin RB, et al. Pathology after eculizumab in dense deposit disease and C3 GN. J Am Soc Nephrol. 2012;23:1229-37.

88. Bomback AS, Smith RJ, Barile GR, Zhang Y, Heher EC, Herlitz $\mathrm{L}$, et al. Eculizumab for dense deposit disease and $\mathrm{C} 3$ glomerulonephritis. Clin J Am Soc Nephrol. 2012;7:748-56. 